\title{
Adsorption and Micelle Formation of Mixed Surfactant Systems in Water. III. A Comparison between Cationic Gemini/Cationic and Cationic Gemini/Nonionic Combinations
}

\author{
Tatsuo Oida ${ }^{1}$, Noriko NaKashima ${ }^{2}$, Shigemi Nagadome ${ }^{2}$, Jeong-Soo $\mathrm{Ko}^{3}$, \\ Se-Woung $\mathrm{OH}^{3}$ and Gohsuke SugiHARA ${ }^{2 *}$ \\ ${ }^{1}$ Fac. Eng. \& Design, Kyoto Institute of Technology \\ (Kyoto 606-0962, JAPAN) \\ ${ }^{2}$ Dept. Chem, Fac. Sci., Fukuoka University \\ (Fukuoka 814-0180, JAPAN) \\ ${ }^{3}$ Dept. Chem., Mokpo National University \\ (Muan, Chonnam 534-729, KOREA)
}

Edited by M. Iwahashi, Kitasato Univ., and accepted June 3, 2003 (received for review April 23, 2003)

\begin{abstract}
A surface tension study (drop volume method) was performed at $30^{\circ} \mathrm{C}$ on micellization and adsorbed film formation of a mixed system of a cationic Gemini-type surfactant with a cationic surfactant in comparison with another mixed system of the same Gemini-type surfactant with a nonionic surfactant. The systems studied were Bis-ammonium Gemini derived from tartaric acid dibromide salt [BAGTB, 1,4-Bis(trimethylammonio)-2,3dodecyloxy butane dibromide] with hexadecyltrimethylammonium bromide (HTAB): BAGTB/ HTAB mixed system and with n-decanoyl-N-methylglucamide (MEGA-10): BAGTB/MEGA-10 mixed system. The data of surface tension $(\gamma)$ vs logarithmic molality plots as a function of mole fraction of surfactant 2 ( 2 corresponds to HTAB or MEGA-10), $X_{2}$, enabled us to determine the critical micellization concentration (CMC), the surface tension at $\mathrm{CMC}\left(\gamma_{\mathrm{CMC}}\right)$, surface excess concentration $\left(\Gamma_{\mathrm{t}}\right)$, the mean molecular surface area $\left(A_{\mathrm{m}}\right)$, the partial molecular area (PMA), and the measures of efficiency of adsorption $\left(\mathrm{pC}_{20}=-\log \mathrm{C}_{20}\right)$ and $\mathrm{CMC} / \mathrm{C}_{20}$ which is available for evaluating the facilitating balance between adsorption and micellization. In addition, a newly defined measure of synergism in surface activity, i. e., the minimum surface Gibbs energy $\left(G_{\min }^{(\mathrm{S})}\right)$ was employed. Based on these data, the examination of synergism in micelle formation and in surface tension reduction elucidated that the Gemini-type surfactant does not exhibit any positive synergism for either BAGTB/HTAB or BAGTB/MEGA-10 mixed systems. Most of these parameters are found to depend conspicuously on the mixing ratio for both mixtures; indicating that the state of adsorbed film is divided into three ranges of $X_{2}$; the lower, the middle and the higher. The compositions of micelles formed at CMC $\left(Y_{2}\right)$ and of adsorbed film $\left(Z_{2}\right)$ equilibinated with bulk solution at a fixed surface tension were estimated.
\end{abstract}

Key words: mixed surfactant systems, adsorption, Gemini, MEGA-10, hexadecyltrimethylammonium bromide, partial molecular area, surface excess concentration, Gibbs adsorption isotherm, Regular solution theory, minimum surface free energy

\footnotetext{
${ }^{*}$ Correspondence to: Gohsuke SugihARA, Dept. Chem, Fac. Sci., Fukuoka University, Nanakuma, Jonan-ku, Fukuoka 814-0180, JAPAN E-mail: sugihara@cis.fukuoka-u.ac.jp
} 


\section{Introduction}

In parallel with the growing development or application of Gemini-type surfactants, studies on mixed systems of conventional or simple surfactants with Gemini type ones have also been increasing in the last decade. Most concern in the studies on mixed surfactant systems is paid to synergism or blending effects in surfactant mixtures (1-9). As the mixing of different species of surfactants, needless to say, has a possibility to result in more useful performance caused by synergism, early representative studies on mixed surfactants have been introduced by a few useful monographs (10-12) and by books composed of systematically collected papers $(13,14)$. Especially with regards to synergism, the monograph by Rosen has given a detailed explanation of the measures to evaluate it for various actual cases (10), and the one by Tsujii has presented important information on the physical chemistry of synergism (12). A strict thermodynamic consideration of the mixed micelles of surfactants (15) and a treatment of the excess thermodynamic quantities of adsorption (16) are also worthy of note.

Following the previous study on the adsorption and micelle formation of mixed systems in water for a combination of top-heavy type surfactants (17), we have reported as a series work on combination of a Gemini surfactant with a nonionic one (18). In the latter a bibliography regarding preparation and properties of Gemini-type surfactants was presented in addition to the physicochemical study of a Gemini/nonionic surfactants mixture; the Gemini was Bis-ammonium Gemini derived from tartaric acid di-bromide salts (BAGTB) and n-decanoyl-N-methylglucamide (MEGA-10) (See Scheme 1). In that paper, from the surface tension measurement (drop volume method), critical micellization concentration (CMC), minimum surface tension at CMC $\left(\gamma_{\mathrm{CMC}}\right)$, surface excess concentration $\left(\Gamma_{\mathrm{t}}\right)$, mean molecular area $\left(A_{\mathrm{m}}\right)$, partial molecular area (PMA) and minimum surface free energy $\left(G_{\mathrm{min}}^{(\mathrm{S})}\right)$ as a function of net mole fraction of MEGA-10 $\left(X_{\mathrm{MEGA}-10}\right)$ were determined. Further, on the basis of the regular solution theory (RST), not only the micellar composition $\left(Y_{\mathrm{MEGA}-10}\right)$ but also the adsorbed film composition $\left(Z_{\mathrm{MEGA}-10}\right)$ were estimated, and additionally, the interaction parameters, $\omega_{\mathrm{R}}$ in the micelle and $\omega_{\mathrm{A}}$ in the adsorbed films were evaluated. From these data we constructed a phase diagram composed of CMC- $X_{\mathrm{MEGA}-10}$ and CMC- $Y_{\mathrm{MEGA}-10}$ curves and another one composed of $m_{\mathrm{t}}$ (total bulk concentration of the surfactants in molality)- $X_{\mathrm{MEGA}-10}$ and $m_{\mathrm{t}}$ $Z_{\text {MEGA-10 }}$ curves. In the combination of BAGTB with MEGA-10, it was found that (i) properties of micelles as well as adsorbed film do depend markedly on the mixing ratio; the different properties are discontinuously varied with changing mole fraction, and (ii) synergism acts little although the interaction parameter values are slightly negative (18), as was found to show no or little synergism for some binary mixtures $(2,3,6)$.

In this paper, the counterpart of BAGTB is a cationic surfactant, hexadecyl trimethylammonium bromide (HTAB). The properties were examined in the same terms as those of BAGTB/MEGA-10 (18) and results will be discussed by making a comparison between MEGA-10 and HTAB mixtures with BAGTB.

\section{Experimental}

\subsection{Materials}

As an optically active Gemini type surfactant having two hydrophilic ammonium groups and lipophilic alkyl chains $(2+2$ type), the present surfactant having two $\mathrm{C}_{12} \mathrm{H}_{25}$ chains was prepared from tetramethyltetramide [I], $\left(\mathrm{CHOHCON}\left(\mathrm{CH}_{3}\right)_{2}\right)_{2}$. After treatment of [I] with alkyl bromide (in the present case, $\mathrm{C}_{12} \mathrm{H}_{25} \mathrm{Br}$ ) to produce O-alkylated tartaramide [II], the reduction of the product [II] was carried out to give the tertiary amines [III] with methyl bromide in acetonitrile, which produced the objective bis-ammonium Gemini surfactant [IV]: $\left[\mathrm{CHO}\left(\mathrm{C}_{12} \mathrm{H}_{25}\right) \mathrm{CH}_{2} \mathrm{~N}^{+}\left(\mathrm{CH}_{3}\right)_{3}\right]_{2} \cdot 2 \mathrm{Br}$, i.e., 1,4-Bis(trimethylammonio)-2,3-dodecyloxy butane dibromide.

The details of the preparation of the present Gemini type surfactants, including Na salts of Bis-sulfate Gemini with alkyl chain whose carbon atoms number ranges 8 to 16 and $\mathrm{Br}$ salts of Bis-ammonium Gemini with

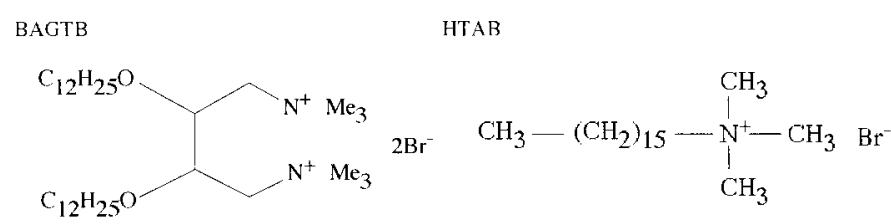

MEGA-10

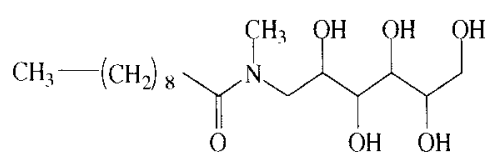

Scheme 1 
$\mathrm{C}_{8} \mathrm{H}_{7}$ and $\mathrm{C}_{16} \mathrm{H}_{33}$, have been described elsewhere (19). In this paper, the compound [IV] is hereafter abbreviated as BAGTB. Hexadecyltrimethylammonium Bromide (HTAB) of guaranteed grade was purchased from NACALAI TESQUE, INC. Kyoto, Japan. As the plot of surface tension $(\gamma)$ vs logarithmic molality gave no minimum coming from impurities, the HTAB was used as received (Lot No. MIN9186). Sodium Bromide, $\mathrm{NaBr}$, was of guaranteed grade from NACALAI TESQUE (Lot No. M2R2659) and used with no further purification.

\section{$2 \cdot 2$ Preparation of Solutions}

Using triple-distilled water, the respective solutions of differing molalities $\left(\mathrm{mol} \mathrm{kg}^{-1}\right)$ were batchwisely prepared from a concentrated stock solution at every 0.1 mole fraction of HTAB $\left(X_{\mathrm{HTAB}}\right)$ in the BAGTB/HTAB mixture. For the solutions with added $\mathrm{NaBr}$, aqueous solutions of $\mathrm{NaBr}$ at given concentrations were used as solvent when they were prepared. [The surfactant solutions with added $\mathrm{NaBr}$ were used for determination of the respective degrees of counterion binding by applying the Corrin-Harkins plot (20)]

\subsection{Surface Tension Measurements}

The surface tension $(\gamma)$ measurements were performed on the basis of the same drop volume method as reported previously; using an automated surface tensio- meter (Yamashita Giken YDS94) the temperature of which was kept at $30.0^{\circ} \mathrm{C}$ with an accuracy of $\pm 0.03{ }^{\circ} \mathrm{C}$ by the use of a temperature control system (Yamashita Giken YCS9211) $(17,18,20)$.

\section{Results and Discussion}

\subsection{Basic Data Obtained Directly from $\gamma$ vs ln $m_{\mathrm{t}}$ Plots}

The plots of surface tension $(\gamma)$ against logarithmic molality $\left(\ln m_{\mathrm{t}}\right)$ are shown in Fig. 1 for the respective single systems and a few selected mixed systems. Fig. 1 indicates that (i) even for mixed systems no minimum appeared around CMC, (ii) the curves of mixed systems are located between those of the two single systems in the order of increased mole fraction of $\operatorname{HTAB}\left(X_{\mathrm{HTAB}}\right)$, and (iii) regarding the minimum of surface tension at CMC $\left(\gamma_{\mathrm{CMC}}\right)$ no remarkable difference is observed among all the systems. Very clear breaks of the curves enable us to easily determine CMCs; these values are tabulated in Table 1.

From Fig. 1 we can evaluate $\mathrm{pC}_{20}$ and $\mathrm{CMC} / \mathrm{C}_{20}$ similarly to the previous work (18) based on Ref.10. The results are listed in Table 1. The $\mathrm{pC}_{20}$ value ranges between 3.75 (for BAGTB) and 3.52 (for HTAB) in the range above $X_{\mathrm{HTAB}}=0.3$, but in the lower $X_{\mathrm{HTAB}}$ region it exceeds 3.75 slightly. On the other hand, $\mathrm{CMC} / \mathrm{C}_{20}$ values in the same lower region below $X_{\mathrm{HTAB}}=0.4$ are also

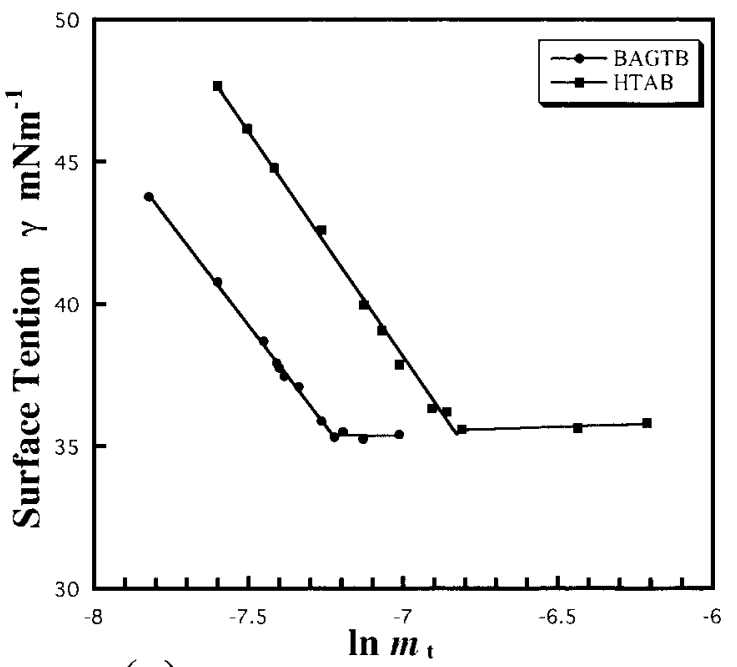

(a)

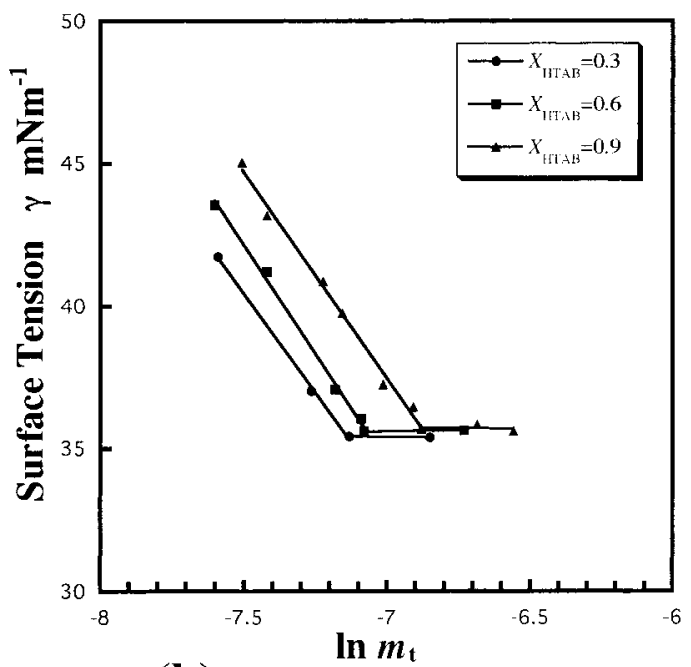

(b)

Fig. 1 The Curves of Surface Tension $(\gamma)$ vs Logarithmic Molality $(\ln m$ ) for the Respective Single Systems (a) and for Three Selected Mixed Systems (b) (the Curves for the Mixed Systems at Different Mole Fractions are between Those of the Single Systems). 
Table 1 Basic Data of BAGTB/HTAB Mixed System in Water at $30^{\circ} \mathrm{C}$.

\begin{tabular}{|c|c|c|c|c|c|c|}
\hline$X_{\text {HTAB }}$ & $\begin{array}{l}\mathrm{CMC} \\
\mathrm{mmol} \\
\mathrm{kg}^{-1}\end{array}$ & $\begin{array}{l}\frac{\Gamma_{\mathrm{t}}}{10^{-6} \mathrm{~mol}} \\
\mathrm{~m}^{-2}\end{array}$ & $\begin{array}{c}A_{\mathrm{m}} \\
\AA^{2} \\
\text { molecule }^{-1}\end{array}$ & $p \mathrm{C}_{20}$ & $\frac{\mathrm{CMC}}{\mathrm{C}_{20}}$ & $\begin{array}{l}\frac{G_{\min }^{(\mathrm{S})}}{\mathrm{kJ}} \\
\mathrm{mol}^{-1}\end{array}$ \\
\hline 0.0 & 0.728 & 1.88 & 88.5 & 3.75 & 4.09 & 18.8 \\
\hline 0.1 & 0.748 & 1.80 & 92.1 & 3.78 & 4.51 & 19.8 \\
\hline 0.2 & 0.754 & 1.83 & 90.6 & 3.79 & 4.61 & 19.3 \\
\hline 0.3 & 0.797 & 2.00 & 83.0 & 3.76 & 4.60 & 17.7 \\
\hline 0.4 & 0.817 & 2.09 & 79.6 & 3.71 & 4.14 & 17.0 \\
\hline 0.5 & 0.835 & 2.27 & 73.2 & 3.67 & 3.86 & 15.6 \\
\hline 0.6 & 0.846 & 2.44 & 68.1 & 3.64 & 3.69 & 14.6 \\
\hline 0.7 & 0.894 & 2.52 & 65.9 & 3.62 & 3.72 & 14.1 \\
\hline 0.8 & 0.959 & 2.67 & 62.1 & 3.58 & 3.68 & 13.4 \\
\hline 0.9 & 1.023 & 2.69 & 61.6 & 3.59 & 3.98 & 13.3 \\
\hline 1.0 & 1.080 & 3.14 & 52.9 & 3.52 & 3.54 & 11.3 \\
\hline
\end{tabular}

higher than that of pure BAGTB and start to decrease with increasing $X_{\mathrm{HTAB}}$, at $X_{\mathrm{HTAB}}=0.2$, except for a sudden maximum reached at $X_{\mathrm{HTAB}}=0.9$. The $\mathrm{pC}_{20}$ is a measure of the efficiency of adsorption (p.84 in Ref.10), while $\mathrm{CMC} / \mathrm{C}_{20}$ is a tool to evalute the facilitating balance between adsorption and micellization. The higher $\mathrm{CMC} /$ $\mathrm{C}_{20}$ values in the lower range of $X_{\mathrm{HTAB}}$ up to $0.3 \mathrm{com}$ pared with that of pure BAGTB suggests that micellization is a little inhibited more than adsorption, or adsorption is facilitated more than micellization; this situation may result from the introduction of some factor (p.143 in Ref.10). As for $\gamma_{\mathrm{CMC}}$ and $\mathrm{CMC} / \mathrm{C}_{20}$ values for the respective single systems will be discussed later.

In order to examine the details of adsorption behavior of mixed systems, evaluation of the surface excess concentration, $\Gamma_{\mathrm{t}}$, and analysis of the composition of adsorbed film phase are necessary. First of all the Gibbs adsorption isotherm must be considered for the present mixed system consisting of a divalent cationic and two mono-valent anionic surfactants.

Let us consider the Gibbs equation for ionic surfactants of $\mathrm{A}^{2+} \mathrm{B}_{2}^{-}$(like BAGTB) and $\mathrm{C}^{+} \mathrm{B}^{-}$(like HTAB). The differenciation of surface tension $\mathrm{d} \gamma$ is generally connected with the chemical potential of species $i, \mu_{\mathrm{i}}$ in water as:

$$
-d \gamma=\sum_{\mathrm{i}} \Gamma_{\mathrm{i}} d \mu_{\mathrm{i}}
$$

where $\Gamma_{\mathrm{i}}$ is the surface excess relative to $\mathrm{H}_{2} \mathrm{O}(21)$. For surfactant $\mathrm{AB}_{2}, \mathrm{~d} \gamma, \Gamma_{\mathrm{i}}$ and $\mathrm{d} \mu_{\mathrm{i}}$ are related as:

$$
-\mathrm{d} \gamma=\Gamma_{\mathrm{A}^{2+}} \mathrm{d} \mu_{\mathrm{A}^{2+}}+2 \Gamma_{\mathrm{B}^{-}} \mathrm{d} \mu_{\mathrm{B}^{-}}
$$

or

$$
-\frac{\mathrm{d} \gamma}{R T}=\Gamma_{\mathrm{A}^{2+}} d \ln a_{\mathrm{A}^{2+}}+2 \Gamma_{\mathrm{B}^{-}} d \ln a_{\mathrm{B}^{-}}
$$

Since the mean activity of $\mathrm{AB}_{2}, a_{\mathrm{AB}_{2}}$, is given by

$$
a_{\mathrm{AB}_{2}}^{3}=a_{\mathrm{A}^{2+}} \cdot a_{\mathrm{B}^{-}}^{2}
$$

and the activity coeffecients are regarded as one (unity) in such a dilute solution as the present one, $a_{\mathrm{AB}}^{3}$ is approximated as $m_{\mathrm{t}}^{3}$. Therefore, the following is derived.

$$
-\frac{d \gamma}{R T}=3 \Gamma_{\mathrm{AB}_{2}} d \ln m_{\mathrm{t}}
$$

On the other hand, as for the adsorption of $\mathrm{CB}$, since the mean activity $a_{\mathrm{CB}}$ is given by $a_{\mathrm{CB}}^{2}=a_{\mathrm{C}^{+}} \cdot a_{\mathrm{B}^{-}} \approx m_{\mathrm{t}}^{2}$, the next equation is obtained.

$$
-\frac{\mathrm{d} \gamma}{R T}=2 \Gamma_{\mathrm{CB}} d \ln m_{\mathrm{t}}
$$

With regards to the mixed adsorbed film, the total surface excess, $\Gamma_{\mathrm{t}}$, is the sum of both surface excesses and is presented as follows, when the composition of $\mathrm{CB}$ in 
the adsorbed film is denoted as $Z_{\mathrm{CB}}$.

$$
\left.\begin{array}{l}
\Gamma_{\mathrm{t}}=\left(1-Z_{\mathrm{CB}}\right) \Gamma_{\mathrm{t}}+Z_{\mathrm{CB}} \Gamma_{\mathrm{t}} \\
\Gamma_{\mathrm{AB}_{2}}=\left(1-Z_{\mathrm{CB}}\right) \Gamma_{\mathrm{t}} \text { and } \Gamma_{\mathrm{CB}}=Z_{\mathrm{CB}} \Gamma_{\mathrm{t}}
\end{array}\right\}
$$

For the adsorbed film composed of binary mixture, eqs.5, 6 and 7 lead to the following relations.

$$
\begin{aligned}
-\frac{d \gamma}{R T} & =3 \Gamma_{\mathrm{AB}_{2}} d \ln m_{\mathrm{t}}+2 \Gamma_{\mathrm{CB}} d \ln m_{\mathrm{t}} \\
& =\left(3\left(1-Z_{\mathrm{CB}}\right)+2 Z_{\mathrm{CB}}\right) \Gamma_{\mathrm{t}} d \ln m_{\mathrm{t}}
\end{aligned}
$$

Therefore we have

$$
\Gamma_{\mathrm{t}}=-\frac{1}{\left(3-Z_{\mathrm{CB}}\right)} \cdot \frac{1}{R T} \frac{d \gamma}{d \ln m_{\mathrm{t}}}
$$

where $Z_{\mathrm{CB}}$ corresponds to $Z_{\mathrm{HTAB}}$ in the present case.

It is noted that in the case of BAGTB/MEGA-10 of the previous paper (18), since MEGA-10 is a nonionic surfactant, the Gibbs adsorption isotherm was presented as:

$$
\Gamma_{\mathrm{t}}=-\frac{1}{\left(3-2 Z_{2}\right) R T d \ln m_{\mathrm{t}}} \frac{d \gamma}{d \ln m_{\mathrm{t}}}
$$

The $\Gamma_{\mathrm{t}}$ values obtained for BAGTB/HTAB mixtures at discrete mole fractions are tabulated in Table 1. The surface excess concentration determined at surface saturation using the Gibbs isotherm (eq.9 or eq.10) is a useful measure of the effectiveness of the surfactant adsorption, since it is the maximum value which adsorption can attain. The effectiveness of adsorption is an important factor in determining such properties of the surfactant as foaming, wetting, and emulsification, since tightly packed, coherent interfacial films have very different interfacial properties to loosely packed, noncoherent films (p.69 in Ref.10). The $\Gamma_{\mathrm{t}}$ is easily translated into mean surface area occupied by a molecule, $A_{\mathrm{m}}$, by the next equation,

$$
A_{\mathrm{m}}=\frac{1}{\Gamma_{\mathrm{t}} \cdot L}
$$

where $L$ is Avogadro's number. Calculated $A_{\mathrm{m}}$ values in $\AA^{2}$ unit are also included in Table 1. Note that when $A_{\mathrm{m}}$ in $\AA^{2}$ is calculated, eq. 11 should be multiplied by $10^{20}$.
The $A_{\mathrm{m}}$ value as a function of mixing ratio or mole fractions of $X_{\mathrm{HTAB}}$ or $Z_{\mathrm{HTAB}}$ can offer us important information concerning the interaction between molecules in the adsorbed film, as will be discussed later.

\subsection{Composition Relations among Bulk Phase $\left(X_{2}\right)$, Micellar Phase $\left(Y_{2}\right)$, and Adsorbed Film Phase $\left(Z_{2}\right)$}

$3 \cdot 2 \cdot 1 \quad$ Phase diagram of singly dispersed (bulk) phase and micellar phase

In Fig. 2(a) CMC values (indicated by closed circles) in mili molality are plotted against mole fraction of HTAB (Surfactant 2) $X_{\text {HTAB }}$, and a solid line is drawn connecting the data points. In the figure the broken line indicates the expected relation when the two surfactants were projected to form micelles of thermodynamically ideal mixing; this curve was obtained by the equations given in the previous paper (17, 23-26). Even if an error margin of around $\pm 5 \%$ is taken into account, the measured values in the range of $X_{\mathrm{HTAB}}=0.3-0.4$ do not coincide with those of ideal mixing, but deviate positively from it.

For any mixed system of either ideal or non-ideal mixing of ionic surfactants 1 and 2, we have applied the following equations including an interaction parameter, $\omega_{\mathrm{O}}$, and degrees of counterion binding, $\beta_{1}$ and $\beta_{2}$ (17, 22-26).

$$
\begin{gathered}
\ln \frac{Y_{1}}{X_{1}}+\kappa_{1} \ln C_{1}^{0}+\left(1-Y_{1}\right)^{2} \omega_{\mathrm{O}}=\kappa_{1} \ln C_{\mathrm{m}} \\
\ln \frac{Y_{1}^{U}}{1-Y_{1}}+\left[U\left(1-Y_{1}\right)^{2}-Y_{1}^{2}\right] \omega_{\mathrm{O}}-\ln \frac{X_{1}^{U}}{1-X_{1}}=U \kappa_{1} \ln \frac{C_{2}^{0}}{C_{1}^{0}}
\end{gathered}
$$

where $U=\frac{\kappa_{2}}{\kappa_{1}}=\frac{\left(1+\beta_{2}\right)}{\left(1+\beta_{1}\right)}$, and $C_{1}^{0}$ and $C_{2}^{0}$ denote the CMC values of the respective single systems 1 and 2 , and $C_{\mathrm{m}}, \mathrm{CMC}$ of each mixed system. Here, the interaction parameter is related to the activity coefficients $f_{1}$ and $f_{2}$ and the micellar composition $Y_{1}$, as follows.

$$
\left.\begin{array}{l}
f_{1}=\exp \left\{\omega_{\mathrm{O}}\left(1-Y_{1}\right)^{2}\right\} \\
f_{2}=\exp \left(\omega_{\mathrm{O}} Y_{1}^{2}\right)
\end{array}\right\}
$$

Applying eqs. [12] and [13] in addition to eq. [14], the 


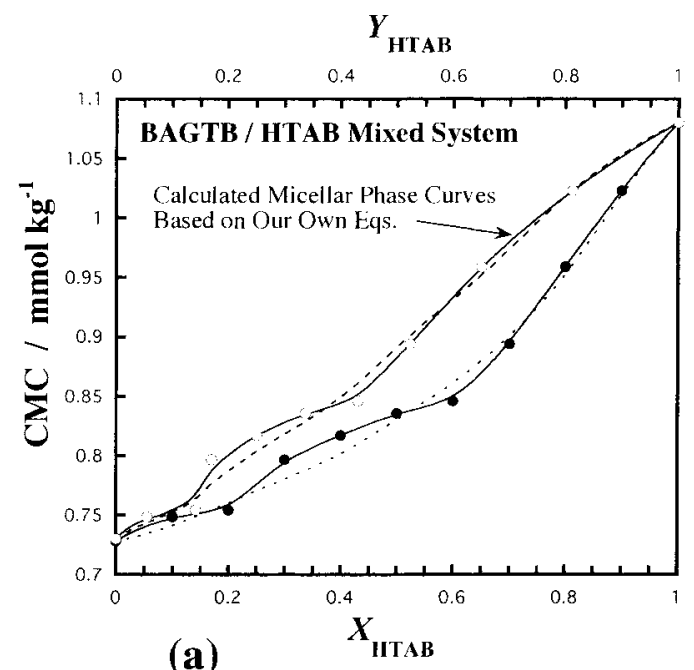

(a)

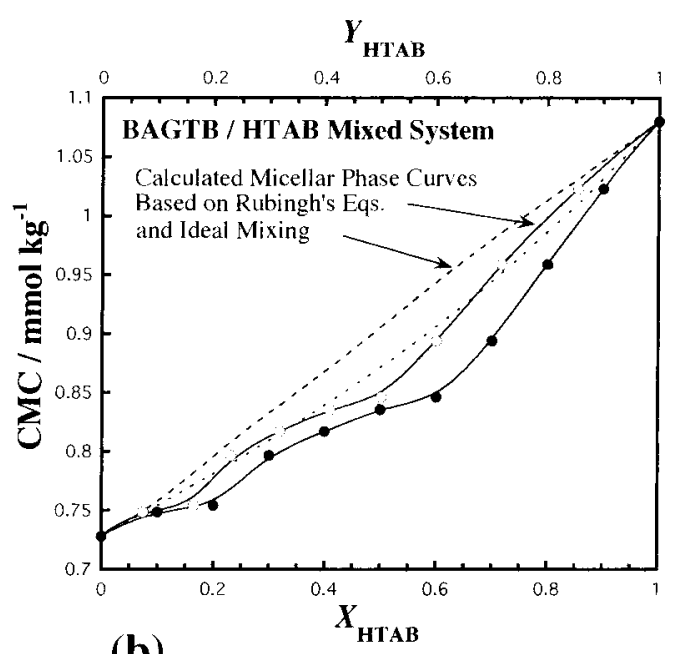

(b)

Fig. 2 Phase Diagram of CMC vs. Composition for BAGTB/HTAB Mixed System at $30^{\circ} \mathrm{C}$. The solid line along closed circles indicating $\mathrm{CMC}$ values as a function of mole fraction of HTAB corresponds to the monomeric phase curve and that along open circles corresponds to the micellar phase curve calculated on the basis of (a) our theoretical equations and (b) Rubingh's equations.

Table 2 Values of CMC, $Y_{\mathrm{i}}, \omega_{\mathrm{R}}$, and $f_{\mathrm{i}}$ for BAGTB/HTAB Mixed Systems.

\begin{tabular}{|c|c|c|c|c|c|c|c|}
\hline$X_{\text {HTAB }}$ & $\begin{array}{c}\text { Ideal CMC } \\
\text { value } \\
\mathrm{mmol} \cdot \mathrm{kg}^{-1}\end{array}$ & $\begin{array}{c}\text { Real-Ideal } \\
=\Delta \text { CMC }\end{array}$ & $Y_{\text {HтAB }}$ & $\omega_{\mathrm{R}}$ & $\omega_{\mathrm{O}}$ & $f_{\text {ВАGTB }}$ & $f_{\text {HТAB }}$ \\
\hline 0.0 & 0.728 & 0 & & & & & \\
\hline 0.1 & 0.753 & -0.005 & 0.074 & -0.14 & 0.0 & 1.00 & 0.87 \\
\hline 0.2 & 0.779 & -0.025 & 0.165 & -0.28 & -0.4 & 1.00 & 0.89 \\
\hline 0.3 & 0.807 & -0.010 & 0.231 & -0.07 & 0.0 & 0.99 & 0.91 \\
\hline 0.4 & 0.837 & -0.020 & 0.319 & -0.11 & -0.1 & 0.98 & 0.93 \\
\hline 0.5 & 0.870 & -0.035 & 0.410 & -0.17 & -0.2 & 0.97 & 0.94 \\
\hline 0.6 & 0.905 & -0.059 & 0.502 & -0.27 & -0.3 & 0.96 & 0.96 \\
\hline 0.7 & 0.943 & -0.049 & 0.600 & -0.23 & -0.2 & 0.94 & 0.97 \\
\hline 0.8 & 0.985 & -0.026 & 0.718 & -0.13 & -0.1 & 0.92 & 0.99 \\
\hline 0.9 & 1.03 & -0.007 & 0.854 & -0.05 & 0.0 & 0.89 & 1.00 \\
\hline 1.0 & 1.08 & 0 & & & & & \\
\hline
\end{tabular}

$\omega_{\mathrm{R}}$ ave. $=-0.16 \quad \omega_{\mathrm{O}}$ ave. $=-0.1$

values of $Y_{\mathrm{HTAB}}, \omega_{\mathrm{O}}$ and activity coefficients $f_{1}$ and $f_{2}$ were determined, as listed in Table $\mathbf{2}$. It is necessary to obtain the data of $\beta_{1}$ and $\beta_{2}$, so the CMC was measured as a function of bromide ion concentration in solution with added $\mathrm{NaBr}$. Applying the Corrin-Harkins plot $(11,27)$, that is, the plot of $\ln \mathrm{CMC}$ against $\ln (\mathrm{CMC}+$ added $\mathrm{NaBr}$ ), the degree of couterion binding was determined as 0.75 for BAGTB and 0.81 for HTAB (the plot is not shown here). Using these values together with the respective CMC values, the theoretical curve for ideal mixing was calculated $\left(\omega_{\mathrm{O}}=0\right)$. The broken curve in Fig. 2(a) corresponds to the CMC- $Y_{2}$ curve of ideal mixing. The real CMC- $Y_{\mathrm{HTAB}}$ curve also exhibits a clear deviation in the range from $Y_{\mathrm{HTAB}}=0.2$ to 0.4 . 
On the other hand, Rubingh has given theoretical equations for relating the composition of micelles formed at $\mathrm{CMC}$ with that of bulk solution; his useful equations have been widely applied to analyze the relations of CMC-compositions (of singly dispersed phase) with micellar phase (28). His equations were derived without taking into account the effect of counterions on mixed micelle formation in the case of ionic surfactant mixtures. It may be said that in his equations a mixed $\mathrm{CMC}$ value itself involves the effect of counterion binding on micelle formation. In other words his equations are conveniently applicable to any combination of ionic /ionic, nonionic/nonionic or ionic/nonionic surfactant mixtures. Rosen has extensively used the equations for evaluating the extent of synergism. For the same purpose, we apply his equation even to the present study. As shown in Fig. 2(b), CMC- $X_{\mathrm{HTAB}}$ and CMC- $Y_{\mathrm{HTAB}}$ curves calculated from Rubingh's equations were used to construct a phase diagram. Calculated micellar composition and the interaction parameter, $\omega_{\mathrm{R}}$, are included in Table 2. The $\omega_{\mathrm{R}}$ values are necessary when synergism in mixed micelle formation is examined as described later. In comparison of Fig. 2(b) and the corresponding figure for BAGTB/MEGA-10 in the previous paper, the latter resulted in comparatively regular changes with $X_{2}$ (18), while the curves giving the relations of CMC vs $X_{2}$ and CMC- $Y_{2}$ for the present BAGTB/HTAB mixture have clear inflection points as shown in Fig. 2(b).

It should be noted that the CMC- $Y$ curves obtained for ideal (dotted line) and real mixed systems from Rubingh's equations (Fig. 2(b)) are considerably different from those of our own equations provided (Fig. 2(a)); the former leads to the larger interaction parameter $\left(\omega_{R}=-0.16\right)$ as well as the apparently larger negative deviation than the latter $\left(\omega_{0}=-0.1\right)$. The apparently larger deviation is regarded as a result without taking into account the counterion binding effect.

\section{$3 \cdot 2 \cdot 2$ Phase diagram of singly dispersed (bulk) phase and adsorbed film phase}

Adsorbed monolayer (Gibbs monolayer) of a given mixed system of surfactants 1 and 2 is equilibrated with singly dispersed species 1 and 2 in bulk phase. Depending on the activity difference between 1 and 2 , the compositions in the adsorbed film $\left(Z_{1}\right.$ and $\left.Z_{2}, Z_{1}+Z_{2}=1\right)$ may differ from that in bulk phase. Similar to the relation between $X_{2}$ and $Y_{2}$, it is important to examine how $Z_{2}$ is related to $X_{2}$ or whether $Y_{2}$ is equal to $Z_{2}$ or not. To answer this question we have employed the following equations to estimate $Z_{2}$ as a function of $X_{2}$, which were derived on the basis of the regular solution theory $(17,18)$. The activity coefficients of 1 and 2 in the adsorbed film, $f_{1}$ and $f_{2}$ can be related to $Z_{2}$ and the interaction parameter $\omega_{\mathrm{A}}$, where $m_{1}^{0}, m_{2}^{0}$ and $m_{\mathrm{t}}$ are refered to as the bulk concentrations of the respective single systems and the total concentration of the mixture, respectively, at a constant surfactant surface tension, i.e., $\gamma_{\mathrm{CMC}}=35.6 \mathrm{mNm}^{-1}$ and $m_{2}^{0}$ is the CMC of HTAB.

$$
\left.\begin{array}{l}
f_{1}=\exp \left[\omega_{\mathrm{A}} Z_{2}^{2}\right] \\
f_{2}=\exp \left[\omega_{\mathrm{A}}\left(1-Z_{2}\right)^{2}\right]
\end{array}\right\}
$$

From analogy with the derivation of Rubingh's equations (28), we obtained the following equations.

$$
\begin{aligned}
& \frac{\left(1-Z_{2}\right)^{2} \ln \left[\left(1-X_{2}\right) m_{\mathrm{t}} /\left(1-Z_{2}\right) m_{1}^{0}\right]}{Z_{2}^{2} \ln \left(X_{2} m_{\mathrm{t}} / Z_{2} m_{2}^{0}\right)}=1 \\
& \omega_{\mathrm{A}}=\frac{\left[\ln \left(X_{2} m_{\mathrm{t}} / Z_{2} m_{2}^{0}\right)\right]}{\left(1-Z_{2}\right)^{2}}
\end{aligned}
$$

Eqs. 16 and 17 simultaneously tell us that if the $m_{1}^{0}, m_{2}^{0}$ and $m_{\mathrm{t}}$ at the given $\gamma$ are determined against net mole fraction $X_{2}$, then the adsorbed film composition $Z_{\mathrm{i}}$ is given by eq. 16 , and $\omega_{\mathrm{A}}$ can be evaluated from eq. 17 by using the $Z_{2}$ values $\left(17,18\right.$, p.394 in Ref.10). The $m_{\mathrm{t}}$ for each mixed system was determined by reading the curves of the $\gamma$ vs $m_{\mathrm{t}}$ plot (Fig. 1) and the read $m_{\mathrm{t}}$ values are listed in Table 3 together with calculated $Z_{2}, \omega_{\mathrm{A}}, f_{1}$ and $f_{2}$. Compared to $\omega_{\mathrm{R}}$ in the micelle, $\omega_{\mathrm{A}}$ is slightly larger in absolute value.

Paying attention to the values of activity coefficients listed in Tables 2 and 3, (i) the values for BAGTB in the micelle as well as in the adsorbed film are greater (nearly equal to 1.0) than those for HTAB in the range from $X_{\mathrm{HTAB}}=0.1$ to 0.5 where BAGTB is the major component, (ii) at $X_{\mathrm{HTAB}}=0.6 \mathrm{BAGTB}$ and HTAB have the same activity coefficient and (iii) in the range between $X_{\mathrm{HTAB}}=0.7$ and 0.9 in the micelle or between $X_{\mathrm{HTAB}}=0.7$ and 0.8 (except for 0.9) in the adsorbed film, the activity coefficients of BAGTB are smaller than those of HTAB which is the major component. 
Table 3 Values of $m_{t}, Z_{\mathrm{i}}, \omega_{\mathrm{A}}$, and $f_{\mathrm{i}}$ for BAGTB $/ \mathrm{HTAB}$ Mixed Systems.

\begin{tabular}{|c|c|c|c|c|c|}
\hline$X_{\mathrm{HTAB}}$ & $m_{\mathrm{t}}$ & $Z_{\mathrm{HTAB}}$ & $\omega_{\mathrm{A}}$ & $f_{\text {BАGTB }}$ & $f_{\mathrm{HTAB}}$ \\
\hline 0.0 & 0.716 & 0.000 & & & \\
\hline 0.1 & 0.747 & 0.078 & -0.14 & 1.00 & 0.89 \\
\hline 0.2 & 0.754 & 0.167 & -0.26 & 0.99 & 0.84 \\
\hline 0.3 & 0.787 & 0.239 & -0.15 & 0.99 & 0.91 \\
\hline 0.4 & 0.82 & 0.321 & -0.13 & 0.99 & 0.94 \\
\hline 0.5 & 0.83 & 0.412 & -0.21 & 0.97 & 0.93 \\
\hline 0.6 & 0.85 & 0.503 & -0.26 & 0.94 & 0.94 \\
\hline 0.7 & 0.89 & 0.601 & -0.23 & 0.92 & 0.96 \\
\hline 0.8 & 0.96 & 0.718 & -0.14 & 0.93 & 0.99 \\
\hline 0.9 & 1.04 & 0.865 & +0.08 & 1.06 & 1.00 \\
\hline 1.0 & 1.08 & 1.000 & & & \\
\hline
\end{tabular}

$\omega_{\mathrm{A}}$ ave. $=-0.2$

BAGTB / HTAB Adsorbed Film

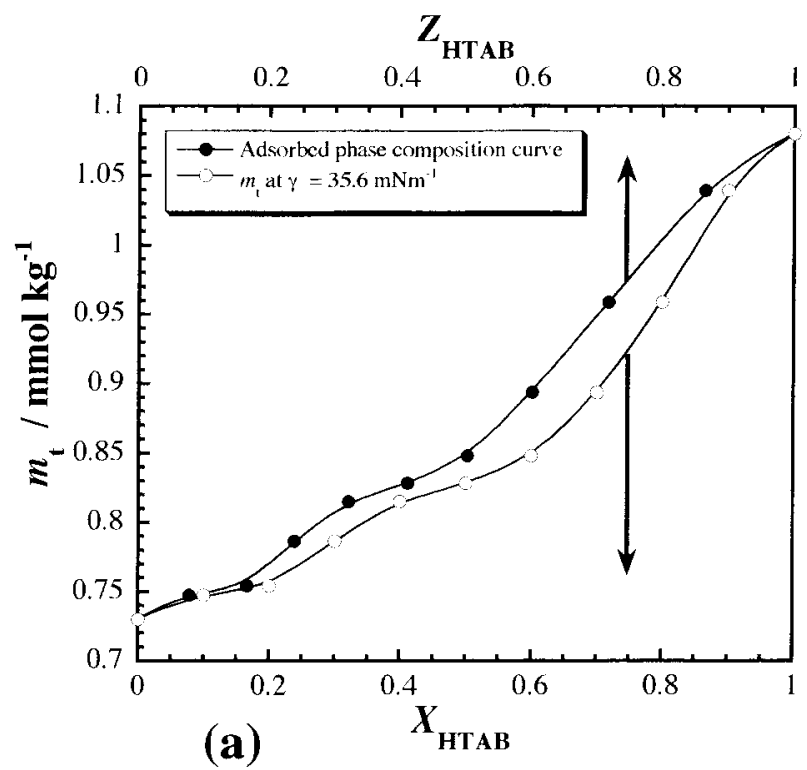

BAGTB / MEGA10 Adsorbed Film

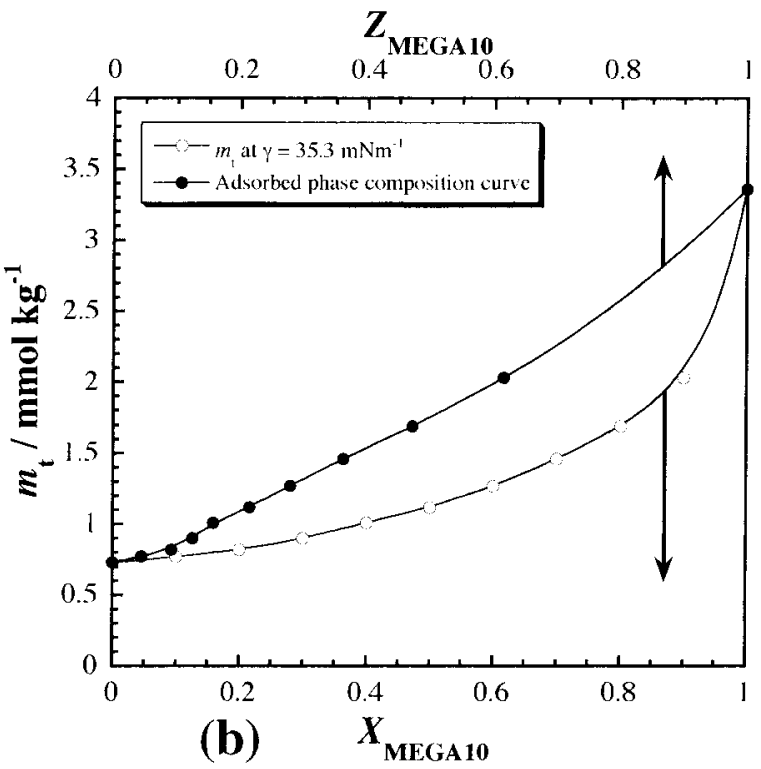

Fig. 3 The Phase Diagrams of Monomers in Bulk Solution and Adsorbed Film at Air/Water Interface for BAGTB/ HTAB Mixed System (a) and for BAGTB/MEGA-10 Mixed System (b) Simulated from the Regular Solution Theory at $30^{\circ} \mathrm{C}$.

In Fig. 3(a) and (b) are shown the results of BAGTB/ HTAB and, for comparison, of BAGTB/MEGA-10, respectively. While the BAGTB/MEGA-10 mixed system gives comparatively regular curves both for $X_{2}-m_{\mathrm{t}}$ and $Z_{2}-m_{\mathrm{t}}$ relations, the BAGTB/HTAB shows, similar to the $X_{2}$-CMC curve shown in Fig. 2, more clearly recognizable inflections in both curves. The shapes of the
$X_{2}-m_{\mathrm{t}}$ and $Z_{2}-m_{\mathrm{t}}$ curves for BAGTB/HTAB mixture resemble those shown in Fig. 2(b), but $Z_{2}$ is not the same as $Y_{2}$. Analyzed values for $Z_{2}, \omega_{\mathrm{A}}, f_{1}$ and $f_{2}$ are tabulated in Table 3. The reason why the curves (seen in Fig. 2(b) and Fig. 3(a)) resemble the respectively corresponding ones is considered to result from the fact that each $m_{\mathrm{t}}$ value is very close to CMC because of little dif- 
ference in $\gamma_{\mathrm{CMC}}$ and from use of similar equations based on the RST.

\section{$3 \cdot 3$ The Properties of the Gibbs Adsorp- tion Monolayer}

The surface excess concentration as a function in the surfactant mixture was evaluated from eq. 9 for BAGTB /HTAB and from eq.10 for BAGTB/MEGA-10 as are shown in Fig. 4(a) and (b), respectively. As was previously reported and is shown in frame (b) the total surface excess $\Gamma_{\mathrm{t}}$ for BAGTB/MEGA-10 has two breaks at $X_{\mathrm{MEGA} 10}=$ ca. 0.45 and ca. 0.75 . Similar to this, $\Gamma_{\mathrm{t}}$ for
BAGTB/HTAB seems to have two breaks at the same mole fractions. Even if the error margin of the data points is taken into account, the existence of the breaks cannot be neglected as a correspondence was observed as inflection points in CMC- $X_{\mathrm{HTAB}}$ and $m_{\mathrm{t}}-X_{\mathrm{HTAB}}$ curves (Fig. 2 and Fig. 3).

Examining the mean molecular (occupation) area, $A_{\mathrm{m}}$, more clearly the breaks are confirmed. In Fig. 5(a), the $A_{\mathrm{m}}$ is plotted as functions of $X_{\mathrm{HTAB}}$ (closed circles) and $Z_{\mathrm{HTAB}}$ (open circles) for BAGTB/HTAB and for BAGTB/MEGA-10 mixed system in (b). Because it is desirable for the behavior of the adsorbed film of a
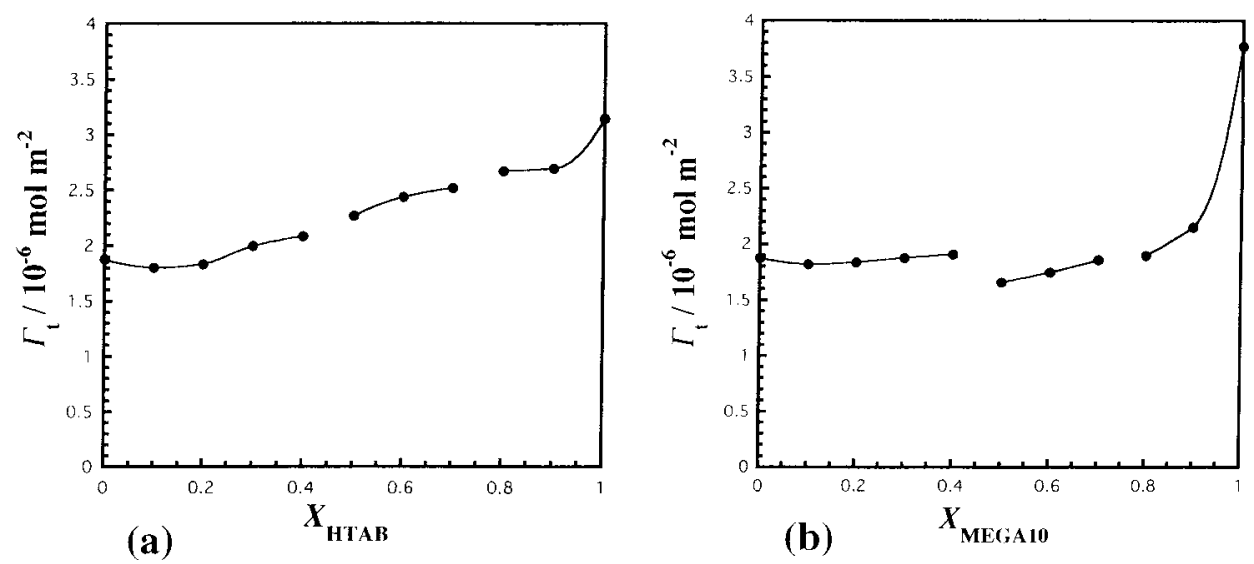

Fig. 4 The Total Surface Excess Concentration, $\Gamma_{\mathrm{t}}$ As a Function of $X_{\mathrm{HTAB}}$ (a) Or $X_{\mathrm{MEGA}-10}$ (b).

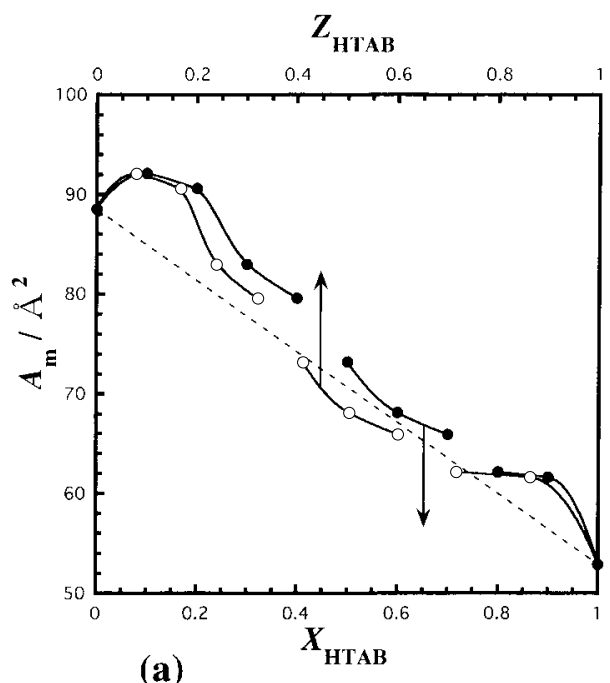

(a)

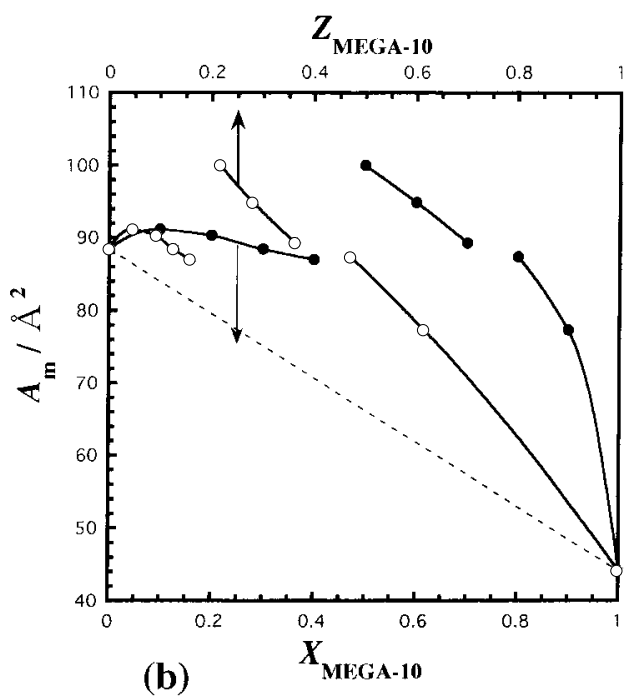

(b)

Fig. 5 The Mean Surface Area $A_{\mathrm{m}}$ Plotted against $X_{\mathrm{HTAB}}$ and $Z_{\mathrm{HTAB}}$ (a), and against $X_{\mathrm{MEGA}-10}$ and $Z_{\mathrm{MEGA}-10}(\mathrm{~b})$. 
given mixed system to be examined in terms of composition of the film, the $A_{\mathrm{m}}$ was plotted against $Z_{\mathrm{HTAB}}$ or

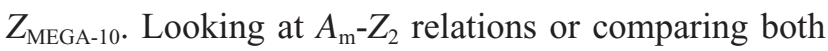
mixed systems, two breaks are commonly found. And if the mixing is ideal, the $A_{\mathrm{m}}-Z_{2}$ relation should be linear as indicated by the dotted line, however, as is seen in Fig. 5(a), the left and right sides as well show a positive deviation except for the central region. In the central region the deviation of $\mathrm{BAGTB} / \mathrm{HTAB}$ is in contrast with that of BAGTB/MEGA-10; the former is slightly negative while the latter's positive deviation is comparatively prominent. In the range of $X_{2}=0.5-0.7\left(Z_{2}=0.4\right.$ -0.6 for the former and $Z_{2}=0.2-0.4$ for the latter), interestingly, the mode of the interaction between hydrophilic groups in BAGTB/HTAB is quite different from that in BAGTB/MEGA-10. That is, HTAB seems to be favorable to BAGTB, but MEGA-10 is unfavorable to BAGTB. This great contrast between the two combinations comes not only from the difference in electorostatic interaction, i.e., between the cationic Gemini and conventional cationic surfactants and between the Gemini and nonionic surfactants but also from the steric effect of head groups on packing each other in the adsorbed layer. The negative values of the interaction parameter $\omega_{\mathrm{A}}$ in the range of $X_{\mathrm{HTAB}}=0.5-0.7$ are greater than those in the other range except for that at $X_{\mathrm{HTAB}}=0.2$ (a very similar trend is found even in $\omega_{\mathrm{R}}$. See Tables 2 and $\mathbf{3}$ ).

From the curve of $A_{\mathrm{m}}$ vs $Z_{2}$, partial molecular area
(PMA) can be determined. As has been discussed previously $(17,18)$, the resultant information on PMA enables us to know about the intermolecular interaction as a function of composition. For this study PMA was evaluated in a similar manner as described previously $(17,18)$. The results are shown in Fig. 6(a) and (b) for BAGTB/HTAB and for BAGTB/MEGA-10. The latter was reproduced from the previous paper for comparison. Both frames clearly demonstrate that there exist two breaks, although the mole fraction giving the breaks differs between the two mixed systems; in (a) $Z_{2}$ =ca. 0.35 and ca. 0.65 , while in (b) $Z_{2}=$ ca. 0.18 and ca.0.45. As $Z_{2}$ approaches absolute zero, HTAB as well as MEGA-10 show an extraordinarily great value of PMA, but this very rapidly decreases in the range below $Z_{2}=$ ca. 0.2 while BAGTB dose little change. In both frames the dotted lines indicate the respective PMA values when the mixing is ideal and accordingly the additivity rule can hold. Both frames show that in the range above $Z_{2}=0.5$ HTAB as well as MEGA-10 does not show any marked change in PMA, while BAGTB at limiting mole fraction $\left(Z_{1}=0\right)$ has an expanded PMA and decreases rapidly (in (a)) or slowly (in (b)) with increased mole fraction of BAGTB (See the right hand side of each frame). This means that the marked expansion of $A_{\mathrm{m}}$ in the higher $Z_{2}$ range comes only from the expanded PMA of BAGTB, especially in the case of the BAGTB/MEGA-10 mixed systems. In regard to $Z_{2}$ dependence the details cannot be further interpreted,
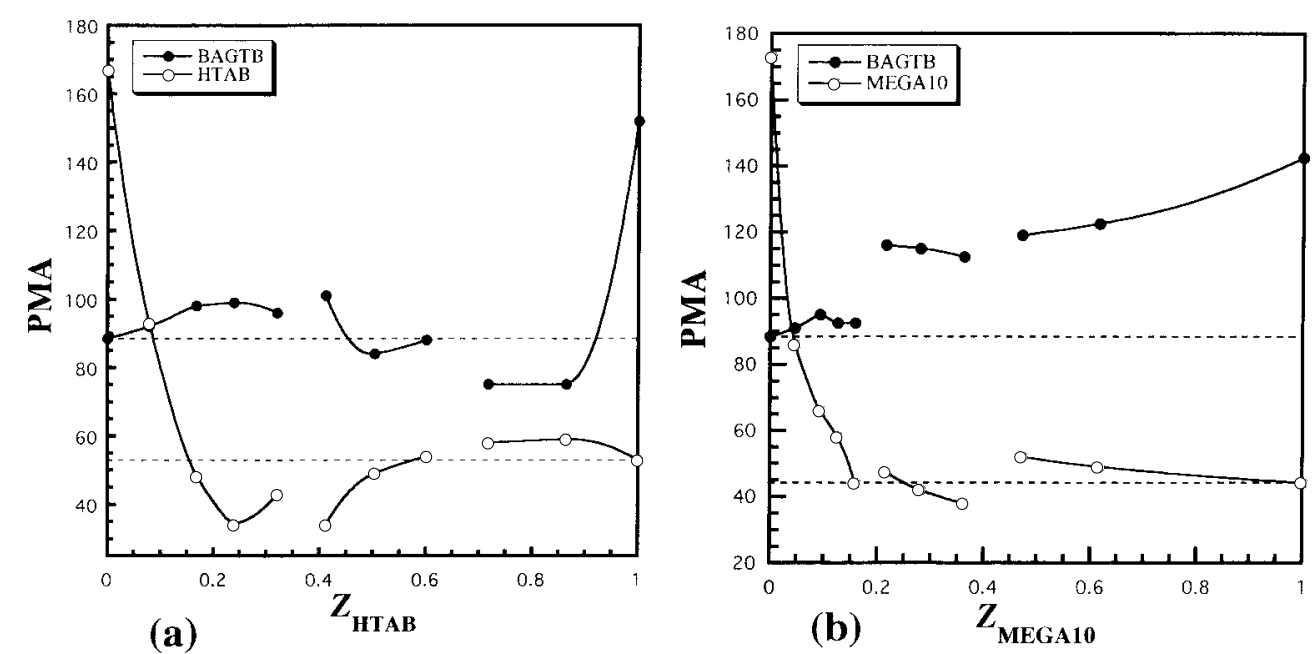

Fig. 6 Partial Molecular Areas (PMA) Determined from the Tangential Slope of Linear Relation at Points on the $A_{\mathrm{m}}$ vs $Z_{2}$ Curve (Fig. 5) as Functions of $X_{2}$ and $Z_{2}$; Two Breaks (Discontinuities) Creating Three Regions are Clearly Demonstrated for Both Mixed Systems. 
however, it may be concluded that the relation of PMA also can be divided into three regions, viz. (i) the BAGTB-major region, (ii) the HTAB- or MEGA-10major region and (iii) the middle region, as has been demonstrated in different aspects. In connection with the composition dependence of a mixed system of a Gemini type surfactant with an ionic one there have been interesting studies reported.

Tsubone and Tajima have studied the aqueous properties of mixed systems of an anionic Gemini surfactant $\left(\left(\mathrm{CH}_{2}\right)_{2}\left[\mathrm{NCO}\left(\mathrm{C}_{11} \mathrm{H}_{23}\right) \mathrm{C}_{2} \mathrm{H}_{4} \mathrm{CO}_{2} \mathrm{Na}\right]\right.$, abbreviated as 212) and a conventional anionic surfactant $\left(\mathrm{C}_{11} \mathrm{H}_{23} \mathrm{CO}_{2} \mathrm{Na}\right.$, soap) in terms of mixed $\mathrm{CMC}$, foam volume and degree of micelle ionization (29), and solubilization of Orange OT by the same surfactant mixture (30). In these studies they found various interesting behaviors as a function of mole fraction of soap in the mixture, eg. (i) positive and negative deviations from ideal mixing in regard to micelle formation were found below and above $X_{\text {soap }}=$ 0.6 , (ii) minimum surface tension $\left(\gamma_{\mathrm{CMC}}\right)$ and maximum foam volume are attained at $X_{\text {soap }}=0.6$ and (iii) in solubilization capacity a break at $X_{\text {soap }}=0.6$ (possible another break at $X_{\text {soap }}=0.1$ ) and a minimum at $X_{\text {soap }}=0.9$ were found (30). They reached the conclusion that the mixture of the anionic surfactants, 212 and soap, forms 2:1 complexes over a broad region of composition during micellization. Similar behavior might be true for the present BAGTB/HTAB and BAGTB/MEGA-10 mixed systems in regard to micellization. In the very near future a solubilization study should be performed even for the present mixtures (18).

We have proposed a thermodynamic quantity for evaluation of synergism in mixing, that is, the free energy of a given surface at equilibrium, $G_{\min }^{(\mathrm{S})}$ (See Table 1 and Fig. 7) which is defined as follows.

$$
G_{\min }^{(\mathrm{S})}=A_{\mathrm{m}} \cdot \gamma_{\mathrm{CMC}} \cdot L
$$

It may be possible to regard $G_{\min }^{(\mathrm{S})}$ as the work needed to make a surface area per mole or the free energy change accompanied by the transition from the bulk phase to the surface phase of solution components. The lower the value of the free energy, the more thermodynamically stable a surface is formed, or the more the surface activity is attained. The extent of lowering the free energy may be a measure for evaluation of synergism in mixed surfactant systems. In Fig. 7 the $G_{\min }^{(\mathrm{S})}$ value of the BAGTB pure system is connected with that of the HTAB (a) or MEGA-10 (b) pure system by a dotted straight line referring to the additivity rule for ideal mixing. The $G_{\min }^{(\mathrm{S})}$ values are given by open circles.

The extent of deviation from the linear relation and the pattern of mole fraction and dependence (divided into three) are evidently recognizable for both mixed systems. Interestingly, in the range of $X_{2}=0.5$ to 0.7 the deviation of BAGTB/HTAB is small ( 0 or slightly positive), in contrast to this, the positive deviation of BAGTB/MEGA-10 is conspicuous. This contrast sug-

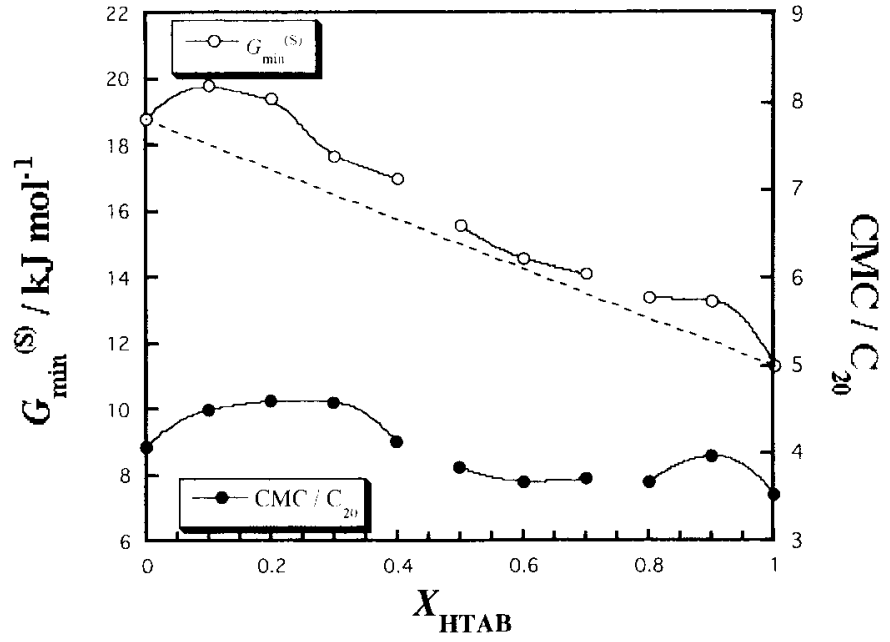

(a)

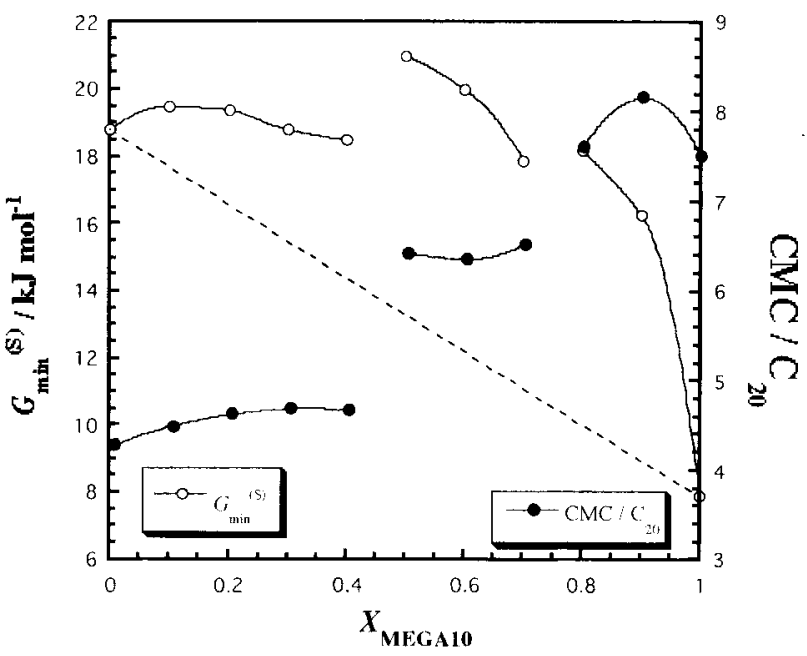

(b)

Fig. 7 The Minimum Surface Gibbs Energy, $G_{\text {min }}^{(\mathrm{s})}$ as well as CMC/C 20 Parameters Plotted against $X_{\mathrm{HTAB}}$ for BAGTB/HTAB (a) and against $X_{\mathrm{MEGA}-10}$ for BAGTB/MEGA-10 (b) Mixed Systems. 
gests that the interaction between head groups between HTAB and BAGTB is favorable for cooperatively reducing the surface tension but the interaction between MEGA-10 and BAGTB head groups is not so favorable. Anyway, the extent of the deviation in $G_{\min }^{(\mathrm{S})}$ from the additivity rule may be regarded as one of the measures for evaluating the synergism with respect to surface activity.

In order to evaluate a synergistic effect on surface activity resulting from the mixing of surfactants 1 and 2 , if an excess amount of the minimum surface energy $\Delta G_{\min (\mathrm{ex})}^{\text {(S) }}$ is considered for the mixed system, it may be defined as the following equation, meaning that $\Delta G_{\min (\mathrm{ex})}^{\text {(S) }}$ at mole fraction $X_{2}$ is the difference of the real value $G_{\min (\mathrm{at}} \underset{\mathrm{S} 2}{\mathrm{~S})}$ less the ideal one, satisfying the additivity rule of ideal mixing.

$$
\Delta G_{\min (\mathrm{ex})}^{(\mathrm{S})}=G_{\min }^{(\mathrm{S})}-\left\{G_{\min (1)}^{(\mathrm{S})}+\left[G_{\min (2)}^{(\mathrm{S})}-G_{\min (1)}^{(\mathrm{S})}\right] X_{2}\right\}
$$

where, $G_{\min (1)}^{(\mathrm{S})}$ and $G_{\min (2)}^{(\mathrm{S})}$ are the minimum surface (Gibbs) free energies of the respective single systems. If an obtained value is negative, it corresponds to a positive synergism as to surface activity. The plot of $\Delta G_{\min (\mathrm{ex})}^{(\mathrm{S})}$ vs $X_{2}$ will directly reflect a synergistic effect (not shown here).

Further, in Fig. 7(a) and (b), the data points of CMC/ $\mathrm{C}_{20}$ are also plotted by closed circles. As has been reported previously (18) and showing again in the frame (b), the $\mathrm{CMC} / \mathrm{C}_{20}-X_{2}$ relation has two breaks corresponding to the other properties already seen in Figs. 3-6. In the BAGTB/HTAB mixed system too, the situation is similar to BAGTB/MEGA-10 in regard to the discontinuity and parallelism of $G_{\min }^{(\mathrm{S})}$ with $\mathrm{CMC} / \mathrm{C}_{20}$. According to the defined conditions of synergism in surface activity (10), firstly, concerning the effectiveness of surface tension reduction, the difference, $\omega_{\mathrm{A}^{-}}$ $\omega_{\mathrm{R}}$, must be negative, and secondly, as to its efficiency, $\left|\omega_{\mathrm{A}}\right|=\left|\ln \left(m_{\mathrm{t}_{2}}^{0} / m_{\mathrm{t}_{1}}^{0}\right)\right|$ must be satisfied. As was pointed out previously (18), neither BAGTB/HTAB nor BAGTB sufficiently satisfies both conditions, meaning that the present two combinations of a cationic Gemini type surfactant, BAGTB with a cationic (HTAB) and a nonionic (MEGA-10) can exhibit little synergism in surface activity.

Finally, again paying attention to the $\gamma_{\mathrm{CMC}}$ values shown in Fig. 1 as well as $\Gamma_{\mathrm{t}}\left(\right.$ or $\left.A_{\mathrm{m}}\right)$ and $\mathrm{CMC} / \mathrm{C}_{20}$ values listed in Table 1 for the respective single systems,
$\Gamma_{\mathrm{t}}$ and $\mathrm{CMC} / \mathrm{C}_{20}$ are markedly different between the two surfactants, while $\gamma_{\mathrm{CMC}}$ is nearly equal. The surface pressure $\Pi_{\mathrm{CMC}}$ or the $\gamma_{\mathrm{CMC}}$ values of surfactants reflect their $\mathrm{CMC} / \mathrm{C}_{20}$ ratio and $\Gamma_{\mathrm{t}}$ as the following equation (Ref.10 p.217, 29,30).

$$
\Pi_{\mathrm{CMC}}=\gamma_{0}-\gamma_{\mathrm{CMC}}=20+n R T \Gamma_{\mathrm{t}} \ln \left(\mathrm{CMC} / \mathrm{C}_{20}\right)
$$

where, $\gamma_{0}$ denotes the surface tension of pure solvent. As described above, the $\mathrm{CMC} / \mathrm{C}_{20}$ ratio is a measure of the tendency to form micelles relative to the tendency to adsorb at the air/water interface. Eq.20 shows us that the $\gamma_{\mathrm{CMC}}$ value involves both the $\mathrm{CMC} / \mathrm{C}_{20}$ ratio and $A_{\mathrm{m}}$ (or $\Gamma_{\mathrm{t}}$ ) values. For applying this equation to the present single systems, the $n$ value must be 3 for BAGTB and 2 for HTAB (see eqs.5 and 6). From the data in Table 1, almost the same $\Pi_{\mathrm{CMC}}$ value $\left(\Pi_{\mathrm{CMC}} / \mathrm{m} \mathrm{Nm}^{-1}=20+\right.$ $7.94 R T$ ) was obtained for both surfactants, just as seen in Fig. 1. This result suggests that in regard to $\Pi_{\mathrm{CMC}}$ (or $\gamma_{\mathrm{CMC}}$ ) the number of ions $n$ (whose surface concentration changes with change in the liquid-phase concentration of the surfactant) also acts effectively in reducing the surface tension of a solvent. Such a binary mixed surfactant system as the present mixture having almost the same $\gamma_{\mathrm{CMC}}$ values may lead to a poor synergism.

In conclusion, the CMC- $X_{2}$ relation of the BAGTB/ HTAB mixed system is neither regular (monotonous) nor markedly deviated from ideal mixing. In this regard, that of the BAGTB/MEGA-10 mixed system gave an apparently regular but to some extent more negatively deviated curve. As for the adsorbed film formation, similar to the BAGTB/MEGA-10 mixture, the combination of BAGTB and HTAB resulted in a marked dependence on the mixing ratio of the binary surfactant system, viz., $\Gamma_{\mathrm{t}}, A_{\mathrm{m}}, \mathrm{PMA}, G_{\min }^{(\mathrm{S})}$ and $\mathrm{CMC} /$ $\mathrm{C}_{20}$ as a function of $X_{\mathrm{HTAB}}$ or $Z_{\mathrm{HTAB}}$ have two breaks (discontinuities). When the mixing ratio of BAGTB: HTAB or MEGA-10 is $1 \sim 2: 9 \sim 8$ or $9 \sim 8: 1 \sim 2$, in other words when one is a notably major component and the other is a minority, the two dimensional packing of binary components is evidently different from intermediate mixtures. It is noted that in the intermediate mixtures remarkably negative synergism was observed for the BAGTB/MEGA-10 mixed system.

\section{Acknowledgments}

This work was in part supported by funds from the 
Advanced Materials Institute, Fukuoka University (Project II) and from the Fukuoka University Central Research Institute (No. 015004).

\section{References}

1. M.J. ROSEN, Z.-H. ZHU and T. GAO, Synergism in Binary Mixture of Surfactants: 11. Mixtures Containing Mono- and Disulfonated Alkyl- and Dialkyldiphenylethers, J. Colloid Interface Sci., Vol. 157, 254-259 (1993).

2. M.J. ROSEN, T. GAO, Y. NAKATSUJI and A. MASUYAMA, Synergism in Binary Mixture of Surfactants 12. Mixtures Containing Surfactants with Two Hydrophilic and Two or Three Hydrophobic Groups, Colloids Surfaces A: Physicochem. Eng. Aspects, Vol. 88, 1-11 (1994).

3. L. LIU and M.J. ROSEN, The Interaction of Some Novel Diquaternary Gemini Surfactants with Anionic Surfactants, J. Colloid Interface Sci., Vol. 179, 454-459 (1996).

4. R. ZANA, H. LEVY and K. KWETKAT, Mixed Micellization of Dimeric (Gemini) Surfactants and Conventional Surfactants. 1. Mixtures of an Anionic Dimeric Surfactant and of the Nonionic Surfactants $\mathrm{C}_{12} \mathrm{E}_{5}$ and $\mathrm{C}_{12} \mathrm{E}_{8}, J$. Colloid Interface Sci., Vol. 197, 370-376 (1998).

5. K. ESUMI, M. MIYAZAKI, T. ARAKI and Y. KOIDE, Mixed Micellar Properties of a Cationic Gemini Surfactant and a Nonionic Surfactant, Colloids Surfaces A: Physicochem. Eng. Aspects, Vol. 135, 117-122 (1998).

6. R.G. ALARGOVA, I.I. KOCHIJASHKY, M.L. SIERRA, K. KWETKAT and R. ZANA, Mixed Micellization of Dimeric (Gemini) Surfactants and Conventional Surfactants: II. CMC and Micelle Aggregation Numbers for Various Mixtures, J. Colloid Interface Sci., Vol. 235, 119-129 (2001).

7. E. ALAMI, K. HOLMBERG and J. EASTOE, Adsorption Properties of Novel Gemini Surfactants with Nonidentical Head Groups, J. Colloid Interface Sci., Vol. 247, 447-455 (2002).

8. K. TSUBONE and K. TAJIMA, Aqueous Properties of Mixed Anionic Gemini Surfactant and Conventional Anionic Surfactant, J. Oleo Sci., Vol. 51, 123-131 (2002).

9. K. TSUBONE and K. TAJIMA, Aqueous Properties of Anionic Gemini Surfactant with N, N'-dialkylamide and Carboxylate Groups in Solubilizing System, J. Oleo Sci., Vol. 51, 371-378 (2002).

10. M.J. ROSEN, Surfactants and Interfacial Phenomena, John Wiley, New York (1989).

11. Y. MOROI, Micelles: Theoretical and Applied Aspects, Plenum, New York (1992).

12. K. TSUJII, Surface Activity: Principle, Phenomena, and Applications, Series in Polymers, Interfaces and Biomaterials (T. TANAKA, ed.), Academic Press, New York (1998).

13. P.M. HOLLAND and D.N. RUBINGH, Mixed Surfactant Systems, ACS Symp. Series Vol. 501, Am. Chem. Soc., Washington DC. (1992).

14. K. OGINO and M. ABE, Mixed Surfactant Systems, Surfactant
Science Series, Vol. 46, Marcel Dekker, New York (1993).

15. K. MOTOMURA, M. YAMANAKA and M. ARATONO, Thermodynamic Consideration of the Mixed Micelles of Surfactants, Colloid Polym Sci., Vol. 262, 948-955 (1984).

16. M. ARATONO, A. OHTA, H. MINAMIZAWA, N. IKEDA, H. IYOTA and T. TAKIUE, The Excess Thermodynamic Quantities of Adsorption of a Binary Nonionic Surfactant Mixture, J. Colloid Interface Sci., Vol. 217, 128-136 (1999).

17. G. SUGIHARA, H. YUTA, A. MIYAZONO, M. ABE and S.-G. $\mathrm{OH}$, Adsorption and Micelle Formation of Mixed Surfactant Systems in Water. I. a Combination of Top-heavy Type Anionic Surfactants, J. Oleo Sci., Vol. 51, 715-728 (2002).

18. G. SUGIHARA, A. MIYAZONO, S. NAGADOME, T. OIDA, Y. HAYASHI and Jeong-Soo KO, Adsorption and Micelle Formation of Mixed Surfactant Systems in Water. II. A Combination of Cationic Gemini-type Surfactant with MEGA-10, J. Oleo Sci., Vol. 52, 449-461 (2003).

19. T. OIDA, Preparation and Properties of Bis-ammonium and Bissulfate Gemini Surfactants Derived from Tartaric Acid, Memoirs Fac. Eng. \& Des. , Kyoto Institute of Technology, Vol. 48, 31-42 (2000).

20. M. hiS ATOMI, M. ABE, N. YOShino, S. LEE, S. NAGADOME and G. SUGIHARA, Thermodynamic Study on Surface Adsorption and Micelle Formation of a Hybrid Anionic Surfactant in Water by Surface Tension (Drop Volume) Measurements, Langmuir, Vol. 16, 1515-1521 (2000).

21. R. AVEYARD and D.A. HAYDON, An Introduction to the Principales of Surface Chemistry, Cambridge Chemistry Texts, Cambridge University Press, London (1973).

22. T.-Y. NAKANO, G. SUGIHARA, T. NAKASHIMA and S.-C. YU, Thermodynamic Study on Mixed Hydrocarbon/Fluorocarbone Surfactant System by Conductometric and Fluorimetric Techniques, Langmuir, Vol. 18, 8775-8785 (2002).

23. G. SUGIHARA, Pressure Effect on Micelle Formation in Mixed Systems of Sodium Prefluorooctanoate with Hydrocarbon Surfactants-Sodium Dodecyl Sulfate, Sodium Decyl Sulfate and Nonanoyl-N-Methylglucamine, in Surfactants in Solution (K.L. MITTAL, ed.), Vol. 7, 397-412, Plnum, New York (1989).

24. G. SUGIHARA, D. NAKAMURA, M. OKAWAUCHI, H. KAWAMURA and Y. MURATA, A Study on the Mixed Micelle Formation of Sodium Dodecyl Sulfate with Sodium Taurodeoxycholate in Aqueous Solutions at $30^{\circ} \mathrm{C}$, Fukuoka Univ. Sci. Reports, Vol. 15, 119-128 (1985).

25. G. SUGIHARA, F. OMOTO-NAGAO, T. TANAKA, S. LEE and Y. SASAKI, Micelle Formation and Counterion Binding in a Mixed System of Cationic Surfactant with Perfluorocarboxylated Ions as Counterion: Dodecylammonium Perfluoroacetate vs Dodecylammonium Perfluoropropionate, J. Colloid Interface Sci., Vol. 171, 246-249 (1995).

26. G. SUGIHARA, Y. ERA, M. FUNATSU, T. KUNITAKE, S. LEE and Y. SASAKI, Micelle Formation of Dodecylammonium Surfactant with Mixed Counterions: Perfluorocarboxylate and Alkanesulfonate Ions, J. Colloid Interface Sci., Vol. 187, 435442 (1997). 
27. G. SUGIHARA and M. HISATOMI, Roles of Counterion Binding in the Micelle Formation of Ionic Surfactants in Water, $J$. Jpn Oil Chem. Soc., Vol. 47, 661-683 (1998).

28. D.N. RUBINGH, in Solution Chemistry of Surfactants (K.L. MITTAL, ed.), Vol. 1, 337, Plenum, New York (1979).

29. K. TSUBONE, T. OGAWA and K. MIMURA, Surface and Aqueous Properties of Anionic Gemini Surfactants Having
Dialkyl Amide, Carboxyl, and Carboxylate Groups, J. Surfactants Detergents, Vol. 6, 39-45 (2003).

30. K. TSUBONE and M.J. ROSEN, Structural Effect on Surface Activities of Anionic Surfactants Having N-acyl-N-methylamide and Carboxylate Groups, J. Colloid Interface Sci., Vol. 244, 394398 (2001). 